\title{
Optimal Design of Opening Ventilation Shaft by Kriging Metamodel Assisted Multi-objective Genetic Algorithm
}

\author{
Azfarizal Mukhtar, Ng Khai Ching, and Mohd Zamri Yusoff
}

\begin{abstract}
Ventilation shaft designs are the most effective devices used for ventilating underground shelter. A Kriging Metamodel assisted Multi-Objective Genetic Algorithm (MOGA) was utilised for the evaluation of an optimal design for the opening ventilation shaft, which improved the ventilation rate of a naturally-ventilated underground shelter. Computational Fluid Dynamics (CFD) was employed as a simulation tool, and the result was validated with experimental data from the previous literature. For the optimisation, three parameters were considered for the effectiveness of the ventilation rate. The generated results found an excellent performance of the strength correlation between parameters and the recommended optimised design. This revealed that an equal opening area has a better ventilation rate for naturally-ventilated underground shelters. Overall, these results can provide support selecting ventilation shaft opening areas in relation to the design of ventilation systems.
\end{abstract}

Index Terms - CFD, optimisation, kriging, multi-objective genetic algorithm, ventilation rate.

\section{INTRODUCTION}

Occupants in underground shelters arefrequently exposed to poor ventilation, high humidity and excess heat. Thus, access tothe external surroundings andhave theadequate fresh air is essential for the health, comfort and satisfaction of the occupants. Most underground shelters often exclude natural ventilation systems and rely entirely ona mechanical conditioning system [1]. This is due to the unpredictable nature of natural ventilation that could interfere with the functioning of mechanical systems in pressurised shelters. Nevertheless, there is a necessity to integrate natural ventilation systems in designing underground shelters to avoid any possibility of the system's failings to function properly.

Usually, ventilation shaftsare utilised for ventilating an underground structure [2], but it is still challenging to determine the opening areas of ventilation shafts suitable for the design. Emswiler et al.[3] found that an equal size of the inlet and the outletventilation shaft produced a higher ventilation rate via simple iterative calculations. Etheridge[4] described the process of determining allowed maximum and minimum sizes of opening areas to achieve the required ventilation rate for the occupants to have comfortable conditions.

In response to this need, a statistical matamodeldata-based can be employed to vary different factors simultaneously.

Manuscript received December 22, 2016; revised April 1, 2017.

Azfarizal Mukhtar is with the Center for Fluid Dynamics, College of Engineering, UniversitiTenagaNasional (UNITEN), Putrajaya Campus, Jalan IKRAM-UNITEN, 43000 Kajang, Selangor, Malaysia (e-mail: azfarizal.mukhtar@gmail.com, PE20591@utn.edu.my)
Three factors were considered here; namely, the opening of the inlet shaft (inch), the opening of the outlet shaft (inch) and the radius elbow shaft $(\mathrm{R} / \mathrm{H})$ on the response of ventilation rate. A commercial CFD software, ANSYS Workbench, was employed, and the geometry used by King [5]was considered for the current study. A schematic drawing and the geometry of the simulation are presented in Fig. 1. Then, careful verification and validation of the CFD model was performed before an optimisation method was conductedvia Kriging metamodel assisted Multi-objective Genetic Algorithm (MOGA). In general, this paper proposes an optimal design of opening areas of ventilation shafts integrated with the CFD simulations.

\section{TERMinOLOGY}

\section{A. Kriging Metamodel}

A metamodel process involves four phases: (a) selecting a DOE method and generating the data, (b) choosing a metamodel (c) fitting the model and (d) verifying the model. In this regard, there are several DOEs and metamodels that canbe used. However, for the current study, the Kriging method was used as a metamodel because it improved the response quality and fitted the higher order variations of the output parameter. In Kriging, a response value from a simulation is globally estimated by a known polynomial, and a random departure from the polynomial [6]:

$$
y(x)=p(x)+Z(x)
$$

Here $y(x)$ is the unknown response of interest, $p(x)$ is a known polynomial function, and $Z(x)$ is realisation of a normally distributed Gaussian random process with mean zero, variance $\sigma^{2}$ and non-zero covariance. More explanation of the Kriging metamodel can be found in the literature [6,7].

\section{B. Latin Hypercube Sampling Design}

Latin Hypercube Sampling Design (LHD) is an advanced form of the Monte Carlo sampling method which avoids clustering samples. It was randomly generated in a square grid across the design space, and there exists no point share in a row or column of the design space. LHD is a complex experimental design that fit with the Kriging metamodel [8].

\section{Multi-objective Genetic Algorithm}

Multi-objective Genetic Algorithm (MOGA) is a variant of the popular Non-dominated Sorted Genetic Algorithm-II (NSGA-II) based on controlled elitism concepts. MOGA is optimal in a Pareto sense, and the set of all such solutions forms the Pareto frontier [6].

It supports multiple objectives and constraints and aims at 
obtaining the global optimum. It also provides a more refined approach compared to other optimisation methods such as desirability functions[9] and Shifted-Hammersley sampling [10].

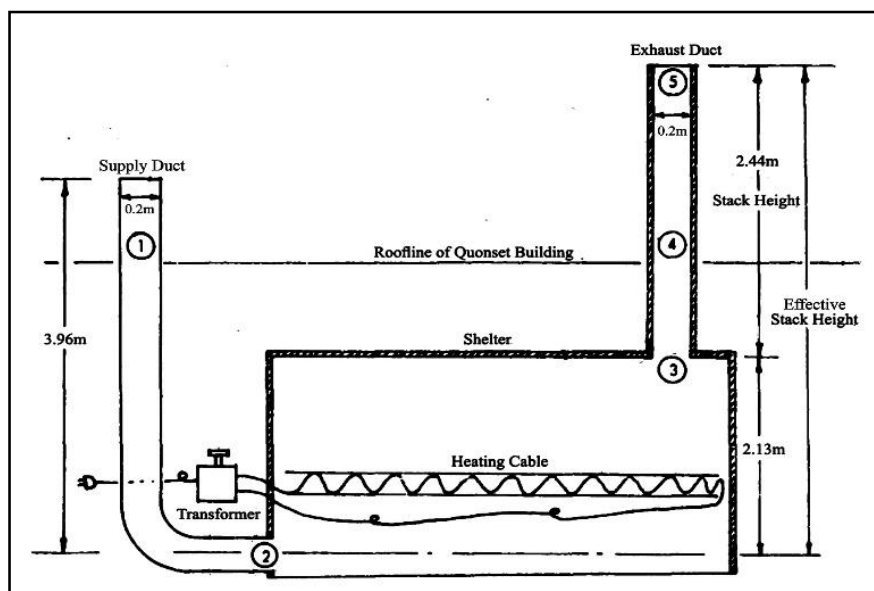

(a) Schematic drawing of experiment

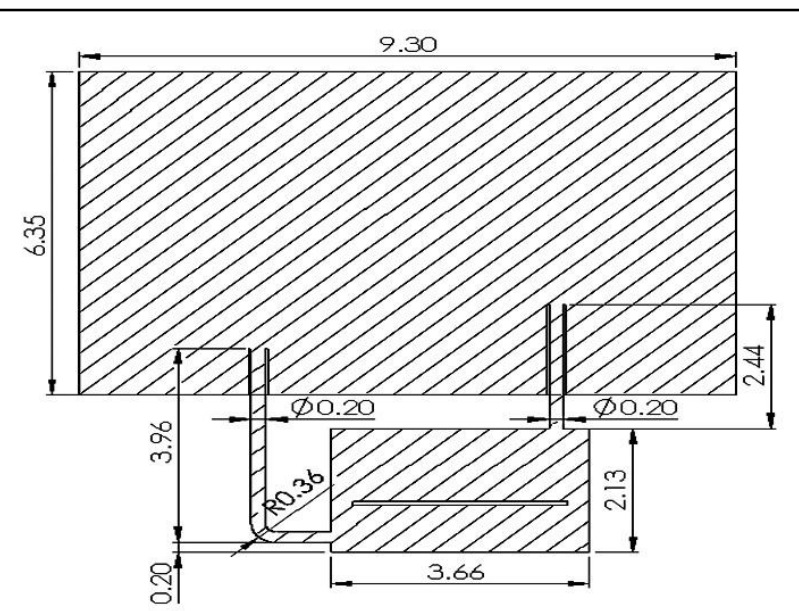

(b) Geometry of simulation

Fig. 1. Schematic drawing and geometry of underground shelter.

\section{METHODS}

\section{A. Computational Fluid Dynamics Modelling}

The 3D CFD model was performed using commercial ANSYS Workbench v16.0, which considered all phases fromthe pre-processing to the post-processing phase. It utilised finite volume method (FVM), and all governing equations were discretized using the second-order upwind schemes.SIMPLEC algorithm was applied to treat the coupling of pressure and velocity. The realizable $k-\varepsilon$ model was applied to model the flow turbulence, and the solution was executed for approximately 400 iterations to attain the steady-state solution. Several mesheswere constructed for grid independence test. The boundary conditionsare labelled in Fig. 2, and the setting is summarisedin Table I.

The core governing equations for the CFD are presented below:

1) Conservation of mass

$$
\frac{\partial \rho}{\partial t}+\nabla \cdot \rho \vec{v}=0
$$

Here $\rho$ is density, $t$ is time and $\vec{v}$ is velocity vector.

2) Conservation of momentum

$$
\rho\left[\frac{\partial \vec{V}}{\partial t}+(\vec{V} \cdot \Delta) \vec{V}\right]=-\nabla p+\nabla \cdot \overline{\bar{\tau}}+\rho \vec{g}
$$

Here $p$ is pressure, $\overline{\bar{\tau}}$ is the viscous stress tensor and $\vec{g}$ is gravitational acceleration. The terms $\rho \vec{g}$ at the RHS of Eq. (2) represent the buoyancy force.

3) Conservation of energy

$\rho\left[\frac{\partial E}{\partial t}+\nabla \cdot(E \vec{v})\right]+\frac{D p}{D t}=\nabla \cdot(k \nabla T)+\Phi+S_{h}$

Here $E$ is the total energy, $t$ is the absolute temperature, $k$ is the fluid thermal conductivity, $S_{h}$ is a source term and $\Phi$ is III. the dissipation function representing the work done by the viscous forces.

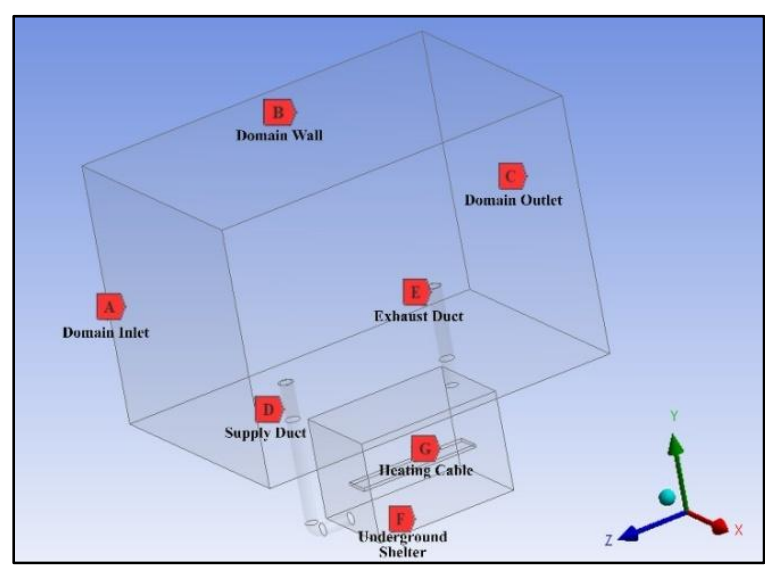

Fig. 2. Boundary conditions.

TABLE I: BOUNDARY CONDITIONS FOR THE SIMULATION

\begin{tabular}{ll}
\hline \hline Domain Inlet & constant velocity, $2.68 \mathrm{~m} / \mathrm{s}$ at aconstant temperature, \\
Domain Outlet & $23^{0} \mathrm{C}$ \\
Domain Wall & zero pressure \\
Supply Duct & adiabatic, no-slip walls $\left(u_{i}=0\right)$ \\
Exhaust Duct & adiabatic, no-slip walls $\left(u_{i}=0\right)$ \\
Heating Cable & heat flux,70 W/m ${ }^{2}$ \\
Underground & adiabatic, no-slip walls $\left(u_{i}=0\right)$ \\
Shelter &
\end{tabular}

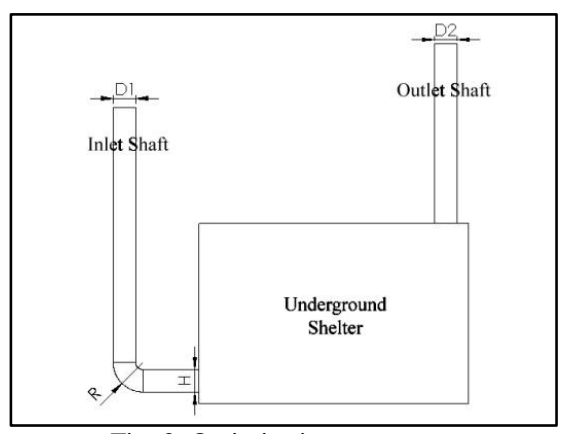

Fig. 3. Optimisation parameters. 


\section{B. Goal Driven Optimisation}

The optimisation process was performed using Design of Experiment (DOE) and Kriging. It was executed utilisingthe Latin Hypercube Sampling Design (LHD) method with central composite design (CCD) sample and two-level factorials (see Table II). As indicated in Fig. 3, three factors and one output were considered for the optimisation i.e. inlet opening, outlet opening and radius elbow shaft $(\mathrm{R} / \mathrm{H})$ which resultantly generated 15 design points that needed to be solved (see Table III). The Kriging metamodel was subsequently used to analyse the design points. The Multi-Objective Genetic Algorithm, on the other hand, was utilised to optimise the defined objective function, which is to maximise the ventilation rate inside the underground shelter. 100 initial sample sets with $70 \%$ of Pareto maximum allowable percentage were generated for MOGA within the optimisation domain.

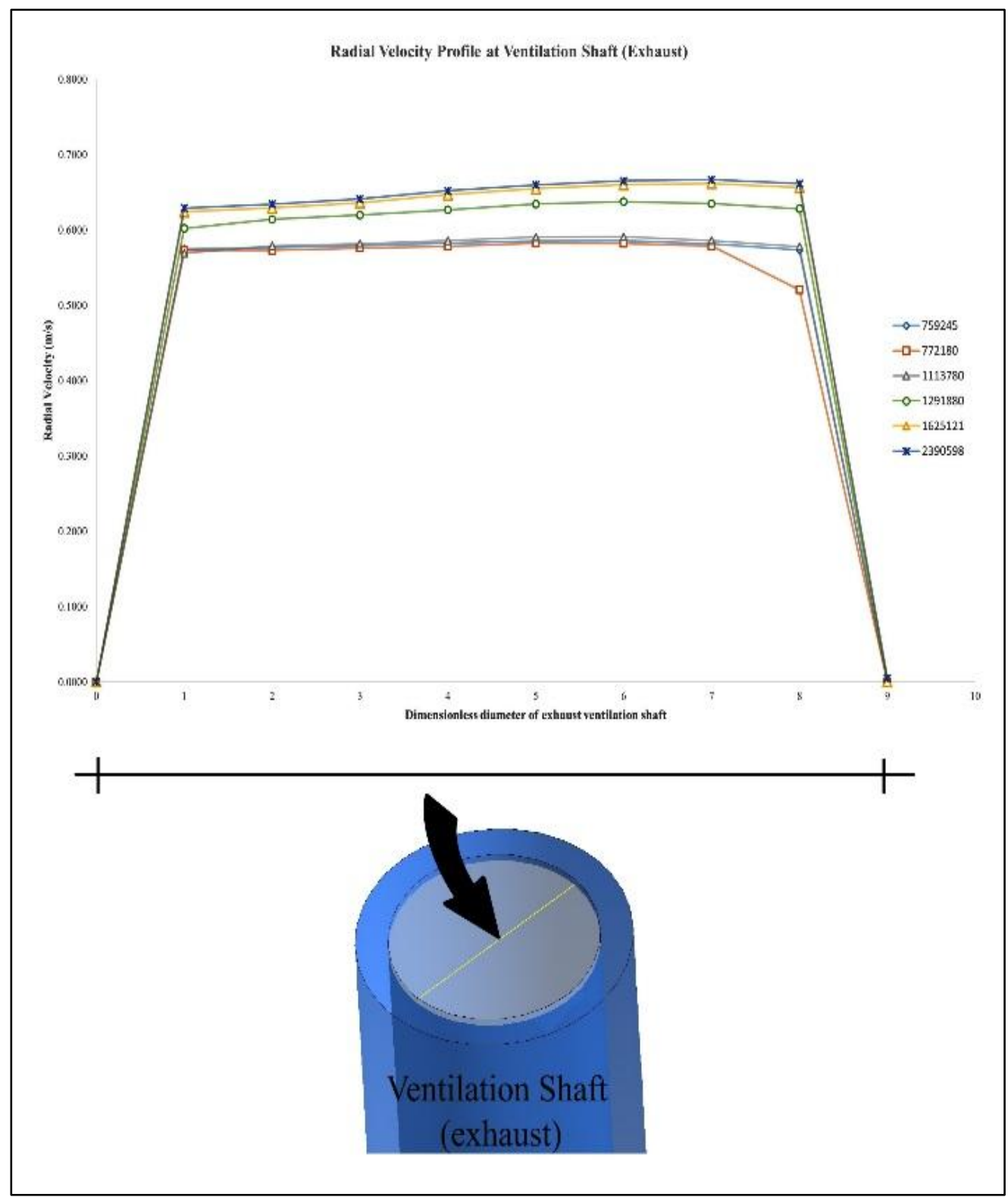

Fig. 4. Grid independence test.

TABLE II: QUANTIFICATION OF FACTOR AND RESPONSE PARAMETERS

\begin{tabular}{|c|c|c|c|c|c|}
\hline \multicolumn{2}{|c|}{ Parameters } & \multirow{2}{*}{\begin{tabular}{l}
\multicolumn{1}{c}{ Name } \\
$\begin{array}{l}\text { Inlet opening } \\
\text { (D1) }\end{array}$
\end{tabular}} & \multirow{2}{*}{$\begin{array}{c}\begin{array}{c}\text { Upper } \\
\text { Bound } \\
\text { (inch) }\end{array} \\
6\end{array}$} & \multirow{2}{*}{$\begin{array}{c}\begin{array}{c}\text { Lower } \\
\text { Bound } \\
\text { (inch) }\end{array} \\
4\end{array}$} & \multirow[t]{2}{*}{ Constraints } \\
\hline \multirow{3}{*}{ Factors } & P1 & & & & \\
\hline & $\mathrm{P} 2$ & $\begin{array}{l}\text { Radius elbow } \\
\text { shaft }(\mathrm{R} / \mathrm{H})\end{array}$ & 2.50 & 0.75 & $\mathrm{R} / \mathrm{H} \geq 0.75$ \\
\hline & P3 & $\begin{array}{l}\text { Outlet opening } \\
\text { (D2) }\end{array}$ & 6 & 4 & - \\
\hline Response & P4 & $\begin{array}{l}\text { Ventilation } \\
\text { Rate }\left(\mathrm{m}^{3} / \mathrm{s}\right)\end{array}$ & & & \\
\hline
\end{tabular}

TABLE III: DESIGN OF EXPERIMENT MATRIX FOR THE KRIGING MODEL

\begin{tabular}{ccccc}
\hline \hline $\begin{array}{c}\text { Design } \\
\text { Points }\end{array}$ & $\begin{array}{c}\mathrm{P} 1 \\
\text { (inch) }\end{array}$ & $\begin{array}{c}\mathrm{P} 2 \\
\text { (inch) }\end{array}$ & $\begin{array}{c}\mathrm{P} 3 \\
\text { (inch) }\end{array}$ & $\begin{array}{c}\mathrm{P} 4 \\
\left(\mathrm{~m}^{3} / \mathrm{s}\right)\end{array}$ \\
\hline 1 & 5.133 & 1.72 & 5.133 & 0.0330 \\
2 & 5.533 & 1.36 & 5.267 & 0.0356 \\
3 & 4.067 & 1.93 & 4.333 & 0.0207 \\
4 & 5.400 & 0.96 & 5.800 & 0.0392 \\
5 & 4.200 & 1.39 & 4.467 & 0.0234 \\
6 & 5.933 & 0.93 & 4.200 & 0.0232
\end{tabular}




\begin{tabular}{ccccc}
7 & 5.267 & 1.80 & 5.667 & 0.0377 \\
8 & 5.800 & 1.47 & 5.533 & 0.0402 \\
9 & 4.600 & 1.34 & 5.000 & 0.0270 \\
10 & 4.467 & 1.83 & 5.933 & 0.0301 \\
11 & 4.867 & 1.40 & 4.733 & 0.0272 \\
12 & 4.333 & 2.12 & 4.600 & 0.0261 \\
13 & 5.000 & 1.43 & 4.867 & 0.0288 \\
14 & 5.667 & 1.74 & 4.067 & 0.0216 \\
15 & 4.733 & 1.37 & 5.400 & 0.0299 \\
\hline \hline & \multirow{5}{*}{ TABLE IV: MAJOR INPUT PARAMETERS } \\
\hline \hline Factors & \multirow{2}{*}{ Relevance } & \multirow{2}{*}{ Response } & R2 & Correlation \\
P3 & 1 & P4 & 0.69 & 0.84 \\
P1 & 0.95 & P4 & 0.29 & 0.57 \\
\hline \hline
\end{tabular}

\section{RESULTS AND DISCUSSION}

\section{A. Verification and Validation}

This model was verified using a grid independence study utilising six different meshes. Fig. 4 indicates that two larger mesh size, i.e. 1.63 and 2.39 million cells, yielded an independent result of radial velocity at the exhaust shaft. The result could be regarded as independence with the grid size, and it was achievedwith the mesh employing 1.63 million cells.

A systematic validation of the CFD model was also performed and carried out according to the Fig 1. The prediction of the simulated ventilation rate was $0.0456 \mathrm{~m}^{3} / \mathrm{s}$, while in the literature [5] it was $0.0477 \mathrm{~m}^{3} / \mathrm{s}$. The percentage difference between these two values were $4.4 \%$, which indicated that the simulated model and its setting approach were in good agreement. Hence, it can be deduced that this CFD model can be applied to simulate the analyses of ventilation efficiency of naturally-ventilated underground shelters.

\section{B. Parameter Correlation}

A correlation matrix was conducted to see how the output response is correlated with other parameters.It was obtained using Pearson's rank correlation and required 100 samples with $5 \%$ of the relevant threshold for filtering along the correlation value.These correlation coefficients were measured based on the sample values. As it can be observed in Fig. 5,colour-coding of the cell indicates the intensity of the correlation, which, when closer to the absolute value of 1 , indicates a stronger relationship. Therefore, it proves that the highest correlation is when the outlet opening is 0.66 followed by inlet opening with 0.39. A scatter plot in Fig. 6 was also produced to generate linear and quadratic trend lines for the most correlated factors. In summation, outlet and inlet openingshas the best relationship with ventilation rate (Table IV). The mathematical model for linear and quadratic trend lines is expressed as follows:

1) Linear trend lines

$$
y=78.016 x+2.6895
$$

2) Quadratic trend lines

$$
y=-4080.7 x^{2}+319.39 x-0.74713
$$

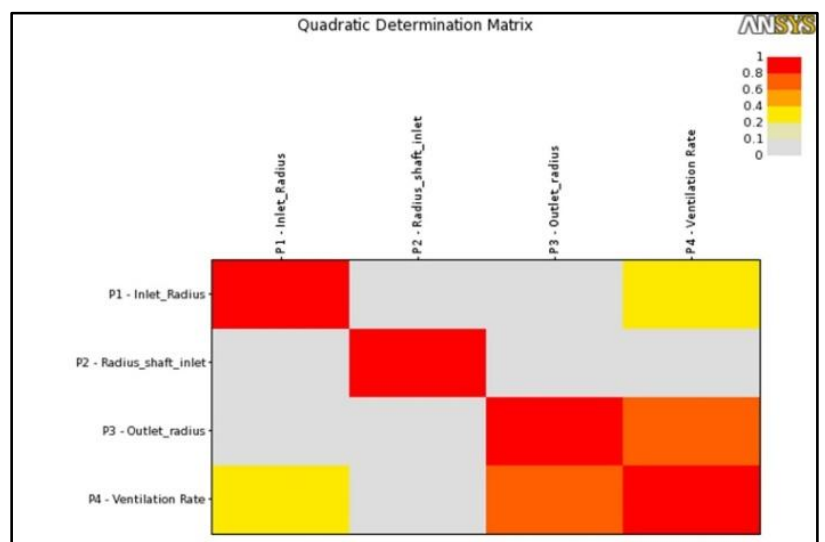

Fig. 5. Quadratic correlation matrix.

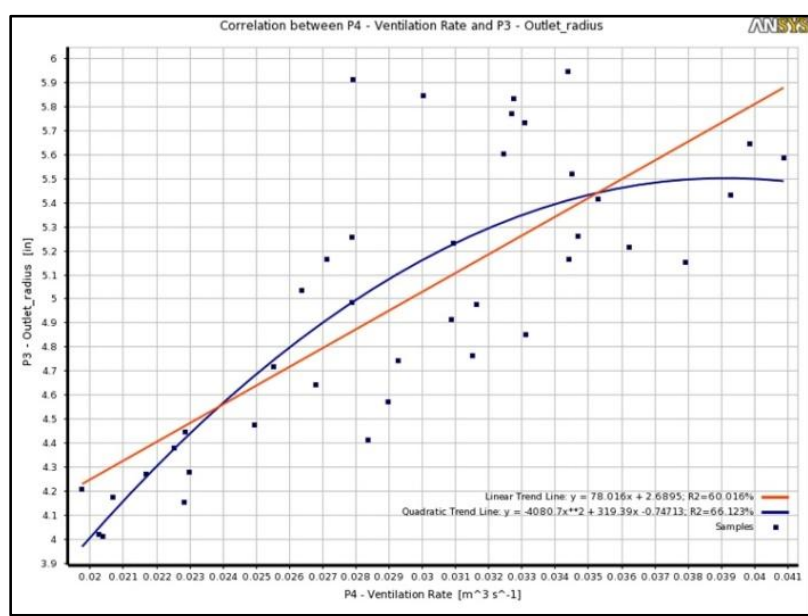

Fig. 6. Correlation chart with quadratic and linear trend lines.

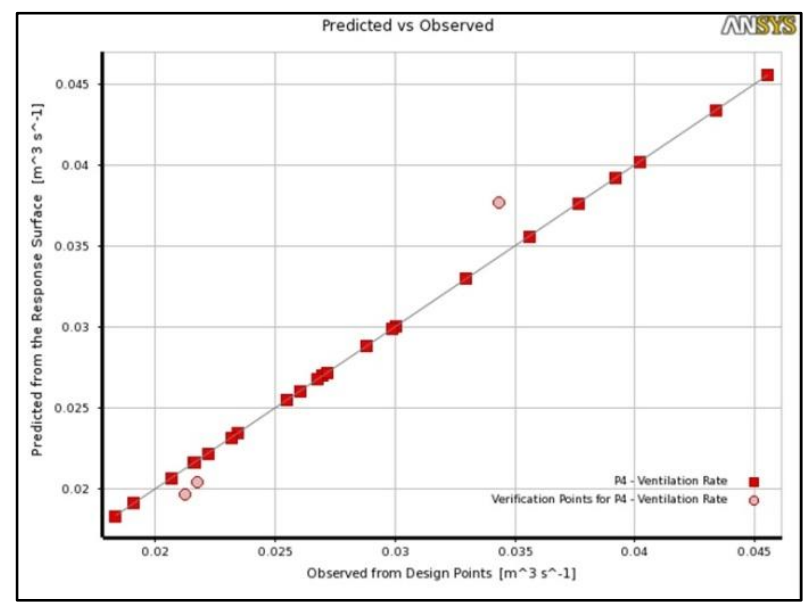

Fig. 7. Goodness of fit.

\section{Kriging Metamodel}

After performing 15 design points suggested by LHD, the generated result was assessedin terms of quality and accuracy by the goodness of fit. Fig. 7 indicates the fit of the regressed response function, by plotting the predicted response values versus the observed values. It seems that the Kriging metamodel used the best linear unbiased predictor-criterion and maximum likelihood estimate. Besides that, the Kriging analysis also produced estimations of the response between major input parameters. As expressed in Fig 8, the highest ventilation rate is obtained at the top right corner of the contour between outlet and inlet openings. It also indicates that the outlet opening has the highest sensitivities in design 
parameters, followed by the inlet opening and radius elbow shaft as the lowest sensitivities (see Fig. 9).

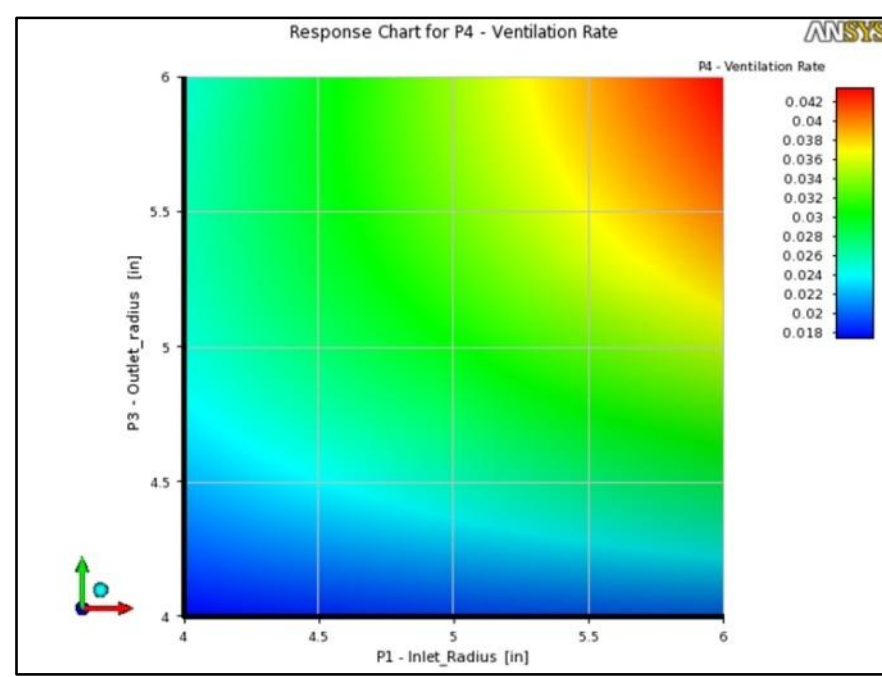

Fig. 8. Response chart.

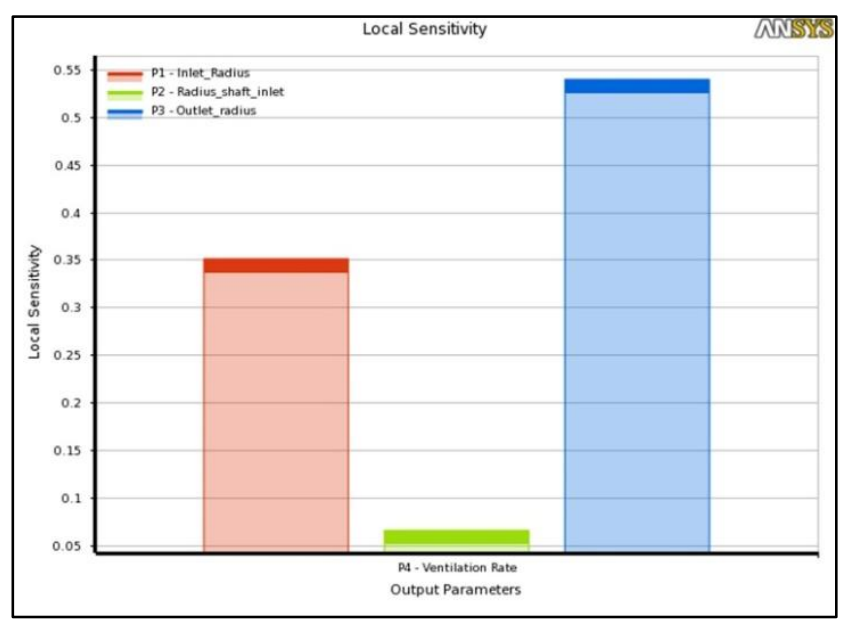

Fig. 9. Local sensitivity.

\section{Optimisation}

By considering parameters (i.e. P1, P2 and P3), the optimised response can be determined. The objective function for the current study was to maximise the ventilation rate. Thus by applying the MOGA method, the best-optimised conditions were subjected to the suggested candidate points as illustrated in Table V. The result indicates that the highest ventilation rate was obtained when the inlet and outlet openings were of equal size and this has been agreed by Emswiler et al. [3]. Also, the convergence stability percentage (see Fig 10) of the MOGA method was $68.21 \%$ where the maximum allowable Pareto percentage was $70 \%$. This convergence criterion looks for population stability, based on the mean and standard deviation of the response.

TABLE V: CANDIDATE POINTS GENERATED FROM MOGA ALGORITHM

\begin{tabular}{ccccc}
\hline \hline $\begin{array}{c}\text { Candidate } \\
\text { Point }\end{array}$ & $\begin{array}{c}\text { P1 } \\
\text { (inch) }\end{array}$ & $\begin{array}{c}\text { P2 } \\
\text { (inch) }\end{array}$ & $\begin{array}{c}\text { P3 } \\
\text { (inch) }\end{array}$ & $\begin{array}{c}\text { P4 } \\
\left(\mathrm{m}^{3} / \mathrm{s}\right)\end{array}$ \\
\hline CP 1 & 5.98 & 0.84 & 5.98 & 0.0453 \\
CP 2 & 5.99 & 0.86 & 5.98 & 0.0452 \\
CP 3 & 5.97 & 0.86 & 5.98 & 0.0451 \\
\hline \hline
\end{tabular}

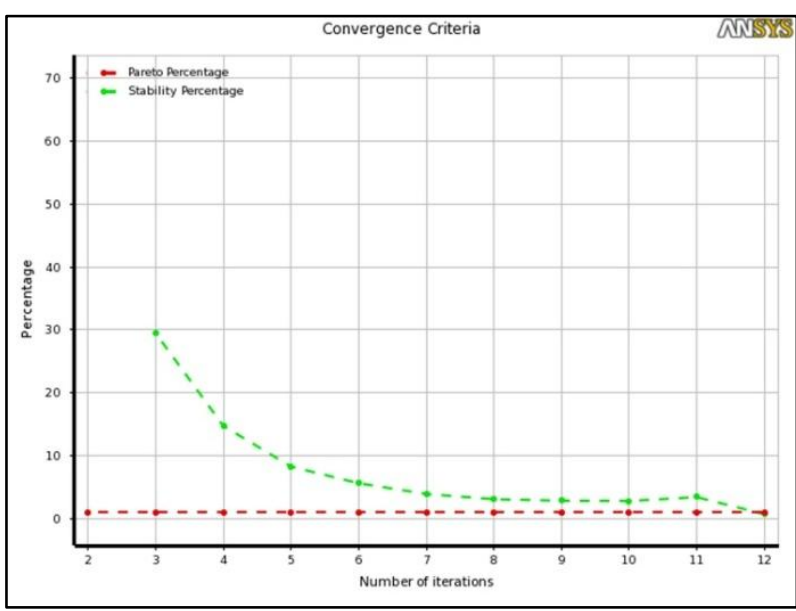

Fig. 10. Converge criteria.

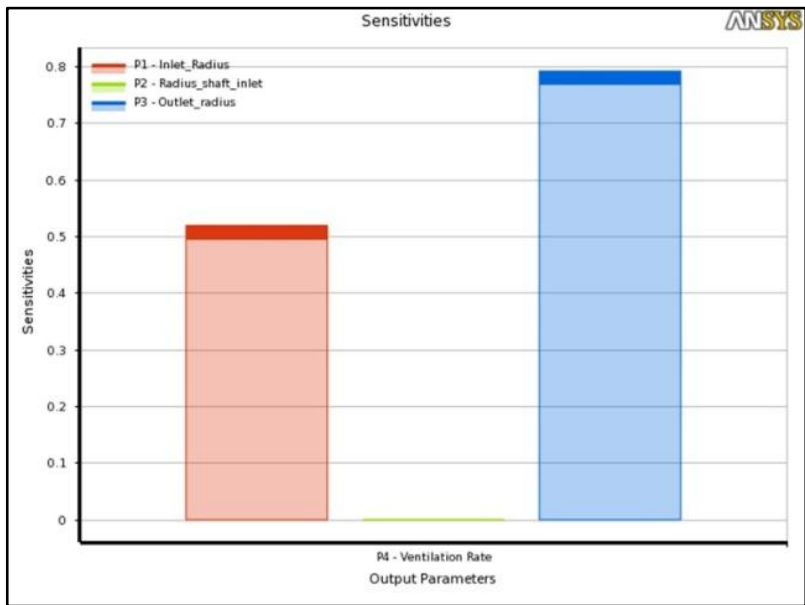

Fig 11. Global sensitivity.

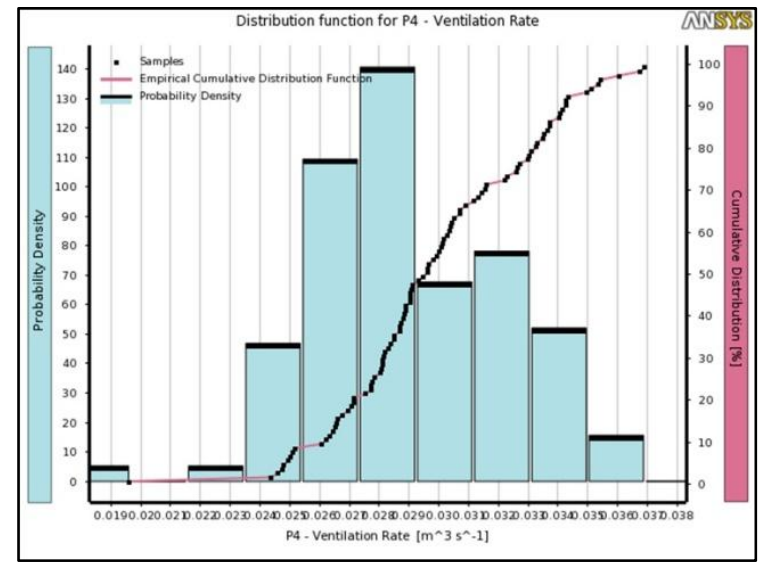

Fig. 12. Normal distribution function.

\section{E. Robust Analysis}

The robust design was used to investigate the performance of the predicted Kriging metamodel response. This was done by incorporating factors, uncertainties and assumptions which were not considered during the Kriging metamodel analysis. The six sigma analysis was conducted for the current study with normal distribution type. The Latin Hypercube Sampling (LHS) algorithm was utilised for the generation of 100 samples, and the solutions were concentrated on the sensitivities of response parameter and statistical distribution of the response of the sample.

As presented in Fig. 11, the sensitivity chart produced the global statistical sensitivities of the values of input parameters. From there, it highlighted that the outlet opening 
produced $79.24 \%$ of the standard deviation response which affects most of the ventilation rate while the inlet opening produced $51.97 \%$ of the standard deviation response. Meanwhile Fig. 12 shows a statistical distribution function of the ventilation rate. It appears that the highest probability density is in the spectrum of $0.0283 \mathrm{~m}^{3} / \mathrm{s}$. The distribution is a symmetric and long-tailed distributionthat is negatively skewed (-0.021973) and has a positively kurtosis (0.021119). Hence, it disclosed the image of normal distributions.

\section{CONCLUSION}

As a conclusion, coupling CFD withan optimisation method were found to be a valuable tool for the analysis and evaluation of factors and responses. This produced comparable results that may assist in the decision-making process towards an optimal design of theopening area of a ventilation shaft. Thus, based on the results obtained, the following summary can be drawn:

1) The outlet opening is the highest correlated factors and has the best relationship with the ventilation rate.

2) The best-optimised condition was subjected to the combination of $\mathrm{P} 1=5.98 ", \mathrm{P} 2=0.84$ " and $\mathrm{P} 3=5.98$ " and the value of ventilation rate, $\mathrm{P} 4$ is $0.0453 \mathrm{~m}^{3} / \mathrm{s}$

3) An equal size of the inlet and outlet ventilation shaft produced a higher ventilation rate.

4) Latin Hypercube Sampling Design (LHD) was a better suited for experimental design of Kriging metamodel.

5) The Kriging metamodel response performed normal distributions of a robust analysis with a symmetric and long-tailed distribution.

\section{ACKNOWLEDGMENT}

The current study was supported by a scholarship provided by YayasanTenagaNasional (YTN) to the first author.

\section{REFERENCES}

[1] C. V. Chestert, Preparing Underground Structures for Civil Defense, Undergr, pp. 160-165.

[2] B. Chenari, J. D. Carrilho, and M. Gameiro Da Silva, "Towards sustainable, energy-efficient and healthy ventilation strategies in buildings: A review," Renew. Sustain. Energy Rev, vol. 59, 2016, pp. 1426-1447.

[3] E. J. Edward and W. C. Randall, "The neutral zone in ventilation," TRANS. Am. Soc. Heat. Vent. Eng, vol. 32, 1926, pp. 59-74.

[4] D. Etheridge, Natural Ventilation of Buildings: Theory, Measurement and Design, First Edit, John Wiley \& Sons Ltd, 2012.

[5] J. C.King, Gravity Ventilation of Underground Shelters, Nav. Civ. Eng. Lab Port Hueneme CA. 1 (1965) 26.

[6] M. Li, G. Li, and S. Azarm, "A kriging metamodel assisted multi-objective genetic algorithm for design optimization," J. Mech. Des, vol. 130, 2008

[7] T. W. Simpson, J. D. Poplinski, P. N. Koch, and J. K. Allen, "Metamodels for computer-based engineering design: Survey and recommendations," Eng. Comput., vol. 17, 2001, pp. 129-150.

[8] J. P. C. Kleijnen, "Kriging metamodeling in simulation: A review," Eur. J. Oper. Res, vol. 192, 2009, pp. 707-716.

[9] G. Derringerand R. Suich, "Simultaneous optimization of several response variables," J. Qual. Technol., vol. 12, 1980, pp. 214-219.

[10] U. M. Diwekar and J. R. Kalagnanam, "Efficient sampling technique for optimization under uncertainty," AIChE J., vol. 43, pp. 440-447.

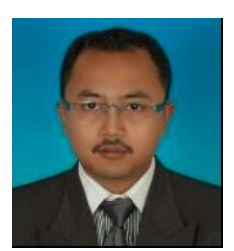

Azfarizal Mukhtar has a master and a bachelor engineering degree in mechanical engineering from the Universiti Teknologi Malaysia. Currently, he is pursuing his $\mathrm{PhD}$ in mechanical engineering at the Centre for Fluid Dynamics, College of Engineering, UniversitiTenagaNasional. He is a chartered engineer registered in the UK (MIMech E) and a former mechanical engineer at the Malaysian Ministry of Defence. Research interests include CFD, Natural Ventilation, Design of Experiment (DOE), Metamodel, Optimisation and Underground Space. 